Bulletin d'Histoire Contemporaine de l'Espagne

$51 \mid 2017$

Les forces politiques durant la Seconde République espagnole

\title{
Dirigismo cultural y disidencia editorial en España
} (1962-1973)

\section{Francisco ROJAS CLAROS}

\section{(2) OpenEdition \\ Journals}

Edición electrónica

URL: http://journals.openedition.org/bhce/783

DOI: 10.4000/bhce.783

ISSN: 1968-3723

\section{Editor}

Presses Universitaires de Provence

Edición impresa

Fecha de publicación: 1 junio 2017

Paginación: 292-295

ISSN: 0987-4135

\section{Referencia electrónica}

Francisco ROJAS CLAROS, « Dirigismo cultural y disidencia editorial en España (1962-1973) », Bulletin d'Histoire Contemporaine de l'Espagne [En línea], 51 | 2017, Publicado el 09 octubre 2018, consultado el 24 septiembre 2020. URL : http://journals.openedition.org/bhce/783 ; DOI : https://doi.org/10.4000/ bhce.783 


\section{Dirigismo cultural y disidencia editorial en España (1962-1973) ${ }^{1}$}

\section{Francisco ROJAS CLAROS}

Esta tesis trata de la influencia del mundo editorial de vanguardia sobre el cambio cultural de los años sesenta y primeros setenta en España. Particularmente, se abordan las tensiones entre el dirigismo cultural del régimen y las ideas que la creciente disidencia intelectual trataba de divulgar, valiéndose del estudio de una serie de editoriales de vanguardia, minoritarias pero de gran trascendencia. Se entiende por dirigismo cultural la tendencia exacerbada de las autoridades del régimen al control de toda manifestación política y cultural que no se adecuase a sus presupuestos ideológicos, fomentando al mismo tiempo la prevalencia de los mismos. Así, el dirigismo cultural puede ser positivo (en forma de propaganda, de mecenazgo cultural y de la concesión del permiso necesario para constituir una empresa editorial y la publicación de cada uno de sus libros), y negativo, con el empleo de elementos represivos como la censura, el secuestro de libros y el silencio administrativo. Cronológicamente, el trabajo abarca los años comprendidos entre 1962 y 1973. Desde la llegada del «aperturista» Manuel Fraga Iribarne al Ministerio de Información y Turismo, hasta el asesinato del almirante Luis Carrero

1 Tesis doctoral defendida el 2 de junio de 2011 en el Departamento de Humanidades Contemporáneas de la Universidad de Alicante. Director: Glicerio Sánchez Recio (Univ. de Alicante). Tribunal: Presidente: Salvador Forner Muñoz (Univ. de Alicante). Secretario: Emilio La Parra López (Univ. de Alicante). Vocales: Jesús A. Martínez Martín (Universidad Complutense de Madrid), Jordi Gracia Garcia (Univ. de Barcelona) y Carme Molinero Ruiz (Univ. Autónoma de Barcelona). La versión ampliada y corregida de la misma constituyó el libro homónimo Dirigismo cultural y disidencia editorial en España (1962-1973), Publicaciones de la Universidad de Alicante, 2013.
Blanco. Un período de cambio económico y social, pero sobre todo cultural, crucial en nuestra historia reciente, y de gran importancia para entender el derrumbe del edificio político del franquismo y el comienzo del proceso de transición política a la democracia parlamentaria en España. Las editoriales disidentes fueron una realidad. El régimen las tuvo muy en cuenta y no tardó en identificarlas como elementos política y socialmente distorsionadores, como se demuestra a lo largo de este estudio.

Como hipótesis de trabajo se ha intentado explicar de qué forma la disidencia editorial trataba de divulgar una serie de ideas que hasta entonces habían sido consideradas «subversivas», teniendo por objetivo socavar los cimientos ideológicos del régimen; y por otra parte, cómo el propio régimen se valió del dirigismo cultural para impedirlo en la medida de lo posible. Todo ello, con la pretensión de demostrar en qué medida contribuyó este tipo de publicaciones al cambio cultural de los años sesenta y al retorno de las libertades en España, partiendo de la idea de que la democracia no es el simple correlato del desarrollo económico y social.

Las fuentes fueron diversas y numerosas. Empezando por las fuentes bibliográficas (es decir, los propios libros, cargados de claves y pistas), las hemerográficas y los testimonios personales, pero prestando especial atención a las archivísticas, referidas sobre todo al Ministerio de Información y Turismo, donde se indica buena parte de las claves y las estrategias propias del dirigismo cultural del régimen en cada momento. Fondos tales como la correspondencia intra e interministerial, los expedientes de censura bibliográfica y el «Registro de Empresas Editoriales».

En cuanto al esquema expositivo, la tesis ha sido estructurada en cinco capítulos, siguiéndose un criterio temático y cronológico, con un último apartado en el que 
se han expuesto las conclusiones principales, que en esencia serían las siguientes.

La política de "apertura» emprendida por Manuel Fraga Iribarne y su equipo ministerial, al menos en el caso que nos ocupa, se redujo a permitir publicar mayor número de libros considerados «de minorías», es decir, aquéllos cuya complejidad de lectura, tiradas limitadas y elevado precio restringieran su acceso a una minoría intelectual económicamente solvente. No hubo voluntad de establecer una liberalización cultural más allá de una simple estrategia de propaganda. De hecho, la Ley de Prensa e Imprenta de 1966 fue enormemente restrictiva, y sólo vino a consolidar en el plano político y judicial la normativa interna sobre libros "de minorías» previamente dictada desde 1963. Sin embargo, hubo un proceso de divulgación de obras de vanguardia a una escala mucho mayor que la deseada por el franquismo. Y se debió, precisamente, a ciertas «fisuras» en la nueva normativa, pero también a la directriz que obligaba a los censores a atender en todos los casos «más a lo que se dice que a lo que parece que se quiere decir». Es decir, a la literalidad del texto, lo cual supuso un cambio prácticamente radical en las reglas de juego. Así, desde los años sesenta, el conflicto principal se libró en un terreno muy específico. El intento de los editores de ampliar el estrecho marco de los «libros para minorías», popularizando su lectura. Por un lado, valiéndose del quality paperback, es decir, libros de pequeño formato con tiradas más amplias y precios asequibles; $\mathrm{y}$ al mismo tiempo, orientando la lectura y codificando el verdadero mensaje dentro del texto publicado. ¿De qué forma? Mediante un proceso de selección. Selección de las temáticas, de los autores, de los textos y de los prologuistas. Como también de todo tipo de añadidos editoriales, tales como notas al pie, dedicatorias, prólogos, estudios introductorios, índices bibliográficos, y un largo etcétera. Todo ello con el propósito de conseguir una lectura alegórica, una «doble lectura». El medio se convirtió en el mensaje. Desde este punto de vista, el concepto de «autocensura editorial» de dichos años no tiene cabida, aunque haya sido utilizado a menudo incluso por los propios editores. Las ideas permanecen en el texto, sólo cambia la forma en que son expresadas. Así, la censura de los años sesenta se movió en esos términos: reescribiendo, orientando y manipulando el significante, sin alterar el significado. El dirigismo cultural del régimen fue consciente de ello. Su objetivo, no obstante, fue evidente: si el medio era el mensaje, el régimen buscaba los medios para restringir la difusión de dicho mensaje mediante una codificación lo más extrema posible. Así, la política de «apertura cultural» significó, en definitiva, la posibilidad de que el mensaje pudiera circular, pero siempre de forma restringida. De ese modo, el Ministerio de Información y Turismo pretendía justo lo contrario de lo que buscaban los editores: es decir, orientar la lectura para evitar toda posible aplicación del texto sobre las realidades del régimen; que fuera una lectura «sólo para eruditos». Fracasados sus intentos (a partir sobre todo de 1968), se optó por controlar directamente las editoriales. Y de una forma completamente extralegal. Primero, utilizando el chantaje administrativo y colocando agentes del Ministerio en sus puestos directivos; y si esto fallaba, procediendo a su cierre administrativo. El «Registro de Empresas Editoriales» no tenía validez más allá de su función coercitiva. El Ministerio cerró con total arbitrariedad editoriales registradas y sin registrar. Sabiendo que el cierre de una editorial suponía un verdadero drama para sus socios y empleados, siendo empresas privadas que permitían a ciertas personas ganarse la vida. Los cierres fueron un atropello en toda regla. Y el miedo, un factor constante durante toda la 
dictadura. El Ministerio también se valió del dirigismo cultural positivo en forma de mecenazgo de tipo monopolístico. El mejor ejemplo de ello se encuentra en la colección de «Libros RTV» (de manos de las editoriales punteras Salvat y Alianza) lanzada en mayo de 1969 con varios propósitos. El propagandístico fue el más evidente, pero también se buscaba lograr un control más directo sobre el proceso de «aperturismo», monopolizándolo, y al mismo tiempo, fortalecer la red de intereses que hasta entonces había sido la base principal integradora del franquismo, una red de intereses cuyos lazos se estaban desarticulando a un ritmo cada vez mayor. El estallido del affaire MATESA evitó recoger los frutos políticos. En todo caso, fue una propuesta interesante con efectos culturales muy positivos, que supuso la entrada en España del libro de bolsillo en estado puro (es decir, obras ya consagradas, de edición en grandes tiradas).

Las empresas editoriales de vanguardia configuraron una serie de «espacios libres» por iniciativa íntegramente privada, para constituir y articular -cada una por separado y todas en conjunto- un espacio público privado de naturaleza política y cultural. Ahora bien, hubo una evolución en la dinámica de todo el proceso, donde la iniciativa corrió siempre por parte de los editores de la disidencia. Inicialmente (y teniendo presente que toda clasificación bibliográfica es discutible), se partió de cuatro grandes bloques principales. En primer lugar, la renovación del Pensamiento, las Artes y las Ciencias Sociales, que fue una renovación basada en traducciones, y también en fuentes clásicas, donde la introducción del marxismo resultó esencial. En segundo lugar, el catolicismo posconciliar progresista, con dos vertientes: la intelectual, y la proyectada por el apostolado seglar, de corte sindicalista, más combativa y por ende más combatida desde la Administración. En tercer lugar, el uso de la reconstrucción histórica como forma de disidencia, con un triple objetivo: recuperar la historia y la memoria, atacar al régimen en sus mismos cimientos ideológicos, y proponer un sistema alternativo para el futuro, siendo consecuente con el pasado recuperado. En cuarto lugar, teorizar sobre la España alternativa, es decir, ofrecer una visión de la realidad nacional, alternativa a la «oficial», más plural y reivindicativa de las nacionalidades históricas, y a la vez creadora de nuevas identidades nacionales, como era el caso de la valenciana, la andaluza y la canaria. Hubo entonces una segunda fase, donde a esos cuatro bloques iniciales se fueron añadiendo otras grandes temáticas, sobre todo desde finales de la década de los sesenta. En primer lugar, cuestiones de política internacional, determinados por el devenir de los acontecimientos más que otra cosa. En segundo lugar, la educación superior, dado el contexto de una universidad convulsa. En tercer lugar, el empleo del humor como arma de combate político, fundamentalmente a través de antologías de autores muy señalados, previamente aparecidos en prensa periódica y publicados de forma unitaria en forma de ensayos de crítica sociopolítica. Y por último, el análisis directo de las realidades del régimen, al socaire del pleno desarrollo de las Ciencias Sociales y sobre todo del periodismo, con la aparición del moderno libro político, que tendrá gran protagonismo durante buena parte de los años setenta. Ese análisis directo fue el objetivo principal de la disidencia desde el principio, y por ende, una de sus grandes conquistas. Así, desde fines de 1969 hubo cambios incluso en el lenguaje utilizado en las publicaciones, algo estrechamente relacionado con el desarrollo del moderno periodismo de opinión políticay cultural, en detrimento del «doble lenguaje» y la «lectura entre líneas», que se fue atenuando. Un lenguaje claro, indispensable para lograr la plena popularización y democratización del libro que perseguían 
los editores. Se estaba afrontando el miedo a la represión porque posiblemente se percibía que ésta ya no daba más de sí: el Estado de Excepción de 1969 había sido su techo, o al menos, así se debió percibir. De ese modo, la disidencia comenzó paulatinamente a denunciar en la prensa la persecución a la que estaban siendo sometidos, abiertamente $\mathrm{y}$ con un doble lenguaje muy atenuado $y$ cargado de ironía. Por otra parte, varias editoriales de vanguardia se organizaron en un frente común, integrando la plataforma «Distribuciones de Enlace», y ofreciendo la colección «Ediciones de Bolsillo», que junto a otras como «Ariel Quincenal» y «Alianza de Bolsillo», serán colecciones de referencia universitaria durante los últimos años de la dictadura, con tiradas de gran entidad.

Para el régimen franquista, con la derrota de los «aperturistas» y el ascenso de Carrero Blanco a la cumbre del poder, el período comprendido entre noviembre de 1969 y diciembre de 1973 fue prácticamente homogéneo en cuanto al dirigismo cultural se refiere, caracterizado por dos elementos fundamentales: intento de «regresión» en el discurso y "continuismo» con la dinámica más autoritaria y represiva del último bienio de Fraga. En un contexto de división interna en el seno del régimen y también de crisis económica, política, social y laboral, y $\sin$ otra capacidad de respuesta ni de reacción que recurrir a la represión. Con la muerte del Almirante Carrero Blanco ya no habrá vuelta atrás, y aunque la censura, la represión y el control cultural siguieron activos hasta al menos 1979, es evidente que el cambio cultural era irreversible. No se puede entender el cambio cultural de los años sesenta sin tener en cuenta el enorme esfuerzo de estas editoriales y, lógicamente, de los personajes que las impulsaron, cuya procedencia política e ideológica pudo ser dispar, pero no así sus objetivos (que fueron mucho más allá que el simple beneficio económico), en medio de un proceso donde el concepto de «cambio generacional» resulta clave. El precio, no obstante, fue muy alto. $\mathrm{Y}$ aunque el balance fue muy positivo, la mayoría de planes editoriales quedaron incompletos. Además, muchas de las obras se editaron mutiladas y con graves modificaciones, y todavía se publican algunas reediciones $\sin$ estar revisadas. En todo caso, es de suponer que el impacto de la disidencia editorial tuvo que ser enorme. Cuanto menos, suficiente para que se formase una elite política alternativa que alcanzaría el protagonismo durante los años setenta y ochenta. Además, la aparición de toda esa bibliografía en los escaparates de las librerías seguramente ofreció por sí misma otro factor de la «percepción de cambio» en gran parte de la sociedad. Al mismo tiempo, y dado que «el medio era el mensaje», la posesión de un libro de bolsillo de vanguardia tuvo que ejercer una poderosa influencia psicológica sobre gentes incapaces de comprender el texto en toda su profundidad. Tras la muerte de Carrero Blanco, y sobre todo tras la muerte del dictador, las actitudes y los objetivos de la disidencia editorial cambiaron. Ya no se trataba de seguir identificando medio con mensaje: se trataba de una lucha, en campo abierto, por la libertad de expresión.

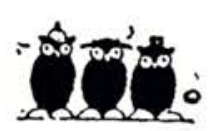

